\title{
Ion Exclusion at the Ice-Water Interface Differs from That at the Hydrate-Water Interface: Consequences for Methane Hydrate Exploration
}

\author{
P. W. Wilson ${ }^{1,2^{*}}$, A. D. J. Haymet ${ }^{2}$ \\ ${ }^{1}$ Institute for Marine and Antarctic Science, University of Tasmania, Hobart, Australia \\ ${ }^{2}$ Scripps Institution of Oceanography, University of California, San Diego, USA \\ Email: * peter.w.wilson@utas.edu.au
}

How to cite this paper: Wilson, P.W. and Haymet, A.D.J. (2017) Ion Exclusion at the Ice-Water Interface Differs from That at the Hydrate-Water Interface: Consequences for Methane Hydrate Exploration. International Journal of Geosciences, 8, 1225-1230. https://doi.org/10.4236/ijg.2017.810070

Received: August 25, 2017

Accepted: October 23, 2017

Published: October 26, 2017

Copyright $\odot 2017$ by authors and Scientific Research Publishing Inc. This work is licensed under the Creative Commons Attribution International License (CC BY 4.0).

http://creativecommons.org/licenses/by/4.0/

\begin{abstract}
When water-ice grows into salt solutions ion species are excluded by the ice differentially due to non-identical solubility in the ice lattice. This causes an electrical potential across the interface during the ice growth process, initially named the Workman Reynolds Freezing Potential, and may be one of the causes for lightning. However, by measuring the voltage between the ice and water, we have found that when tetrahydrofuran hydrate crystals are grown into salt solutions all ion species are excluded equally and the potential does not manifest. When considered together, this marked difference in ion exclusion scenarios may have ramifications for hydrate exploration because of the chlorine anomaly, which is often used as an indicator of the presence of hydrate reserves.
\end{abstract}

\section{Keywords}

Tetrahydrofuran Hydrate, Ion Exclusion, Chlorine Anomaly, Ice, Exploration

\section{Introduction}

It is estimated that about $90 \%$ of natural gas hydrate on Earth is methane hydrate, with potential quantities well above the level of carbon stored as fossil fuel. In some permafrost regions water-ice might also be expected to exist alongside, or perhaps not far above, the hydrates [1]. During hydrate explorations pore-water chlorine anomalies are often used to estimate gas hydrate volumes, with non-standard levels of $\mathrm{Cl}^{-}$taken as an indicator of the presence of gas hydrates under the sea floor [2] [3]. The rationale for using $\mathrm{Cl}^{-}$is based on the exclusion 
of salt from the hydrate crystal lattice during hydrate formation in the sediment and the respective fresh water release when decomposition is initiated during recovery. That is, the fresh water released has less $\mathrm{Cl}^{-}$than would be found in normal sea water for that region. The connection between shallow water hydrates, where water-ice may also form in very cold regions of Earth and this chlorine anomaly is in need of further investigation, as we outline below.

Hydrate exploration technologies are complicated and have many uncertainties. These $\mathrm{Cl}^{-}$assumptions and rationale rely on the total exclusion of ions from the cages of water making up the hydrate structures during hydrate formation and this does appear to be the case. While in general there seems to be good agreement between $\mathrm{Cl}^{-}$values changing and the actual presence of hydrates it must be noted now that the ion exclusion from hydrates and from water-ice are not the same. Full and equal ion exclusion during gas hydrate formation has always been (correctly) assumed [4] [5], but if water-ice is growing in the region during the measurements, it may lead to an erroneous $\mathrm{Cl}^{-}$interpretation. In the $0-25 \mathrm{~m}$ depth range of the sediment at the sea floor the $\mathrm{Cl}^{-}$anomaly is typically found in the 280 to $350 \mathrm{mM}$ range where a $40 \mathrm{mM}$ drop in $\mathrm{Cl}^{-}$is generally taken to indicate the presence of hydrates [3] [6]. In fact, much is inferred about potential hydrate reserves from measured $\mathrm{Cl}^{-}$anomalies where even changes as little as $0.5-5 \mathrm{mM}$ are thought to be significant [7] [8]. The results presented here, however, have implications in areas where fresh water-ice may also be growing near the hydrate at the time of the measurement or where water flushed from growing ice may find itself mixed with sea water in the hydrate region. Pressure precludes water-ice in deep water but off-ice shelves and in water reserves under permafrost there may exist regions where these findings become significant. Such an analysis is beyond the scope of this report.

In 1948, Workman and Reynolds [9] discovered that an electric charge separation occurs during freezing of (slightly) ionized water. Several workers have since shown that when dilute solutions of particular salts such as $\mathrm{NaCl}, \mathrm{KCl}$, and $\mathrm{NH}_{4} \mathrm{Cl}$ freeze relatively rapidly, a strong but transient potential difference of up to several hundred volts is established between the solid and liquid phases [10] [11]. This electric charge separation is commonly referred to as the Workman-Reynolds Effect, or Workman-Reynolds Freezing Potential (WRFP). We have recently repeated many of those measurements [4] [12]. Basically, we find with dilute aqueous solutions that measured voltages are sensitive to salt species, salt concentration, ice growth rate, ice crystal face, and the external load resistance of the measuring device [13].

Our results, typical for a single growth rate of ice, grown as polycrystalline ice, are shown in Figure 1, where it can be seen that the measured voltage shows a maximum as a function of dilution, in this case for $\mathrm{NaCl}$ frozen at $16 \mu \mathrm{ms}^{-1}$ that maximum occurs at about $5 \times 10^{-4} \mathrm{M}$. The positive voltage is produced because $\mathrm{Na}+$ ions are excluded more efficiently from the ice lattice than $\mathrm{Cl}^{-}$ions. It must be noted however that the voltage is transient and reduces to zero even before 


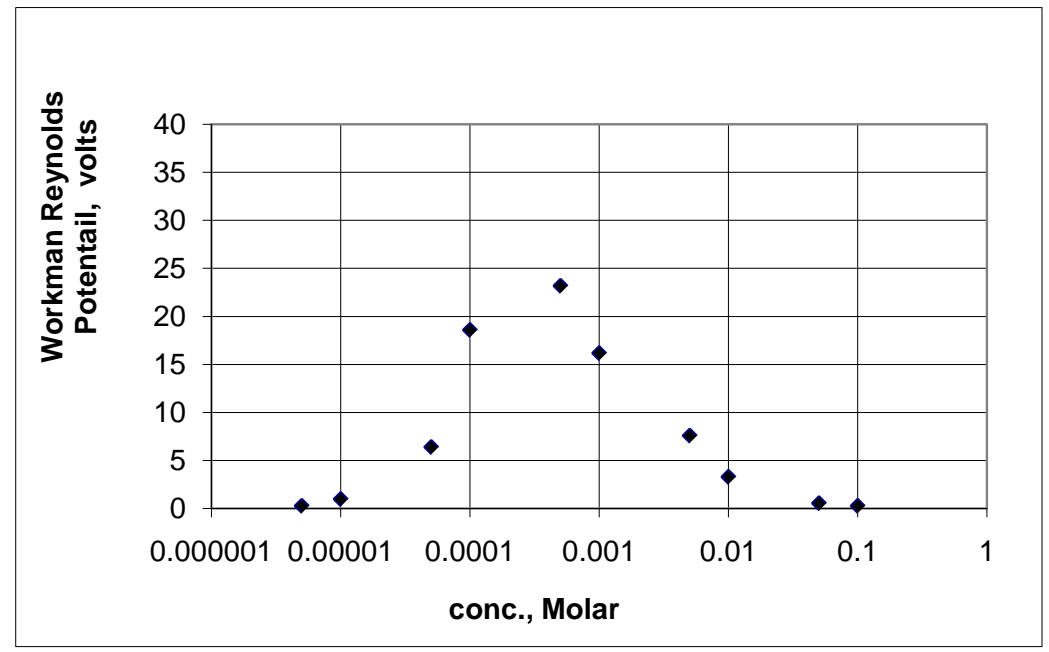

Figure 1. Plot of Freezing Potential (WRFP) measured as a function of ion concentration for polycrystalline ice grown at $16 \mu \mathrm{ms}^{-1}$. Such voltages agree very well with all other published reports of the effect, where all reports, other than those of Haymet and Wilson, have also involved polycrystalline ice.

the growth of the ice is complete [12], as ions within the ice are either neutralized or migrate back to the interface.

Here, we report the markedly different effect which is seen when hydrates of tetrahydrofuran are grown. Clearly THF hydrates are not methane and are not fully representative of hydrates formed at high pressure, but they are often used as a model system. A 17-water fully enclosed cage, for example, may not mimic the THF structure but nonetheless this effect, and its comparison to water-ice, is of interest and in need of further investigation (Figure 2).

In 2008 Wilson and Haymet made mention of the difference between water-ice and THF hydrate grown as single crystals and measured in the method described here [5]. We commented that hydrates fully exclude all species of ion and so the effect is lost and the WRFP is zero, but indeed it remains a possibility that the hydrate crystal is equally porous to both positive and negative ions. What we now show is the comparison for polycrystalline ice and for polycrystalline hydrates grown into similar ion concentrations at growth rates similar to those we previously used. Figure 3 shows typical results of WRFP measured when hydrate of tetrahydrofuran (THF) formed at $81 \mathrm{wt} \%$ water is grown into salt solutions, for the same salt concentrations at which water-ice has been grown. The THF was nucleated rapidly and with multiple nucleation sites, forming multiple small initial crystals and so allowing multiple larger crystals to grow into the salt solution. This is in contrast to our previously published reports [5] [12] using single water-ice crystals and hydrate crystals grown from a single nucleating site and with attention to allowing only a single crystal with known crystal face (in the case of water) to grow as the interface with the solution.

What we find here is that the voltage formed is consistently less than $100 \mathrm{mV}$ over the range of concentrations measured. The value of the freezing potential 


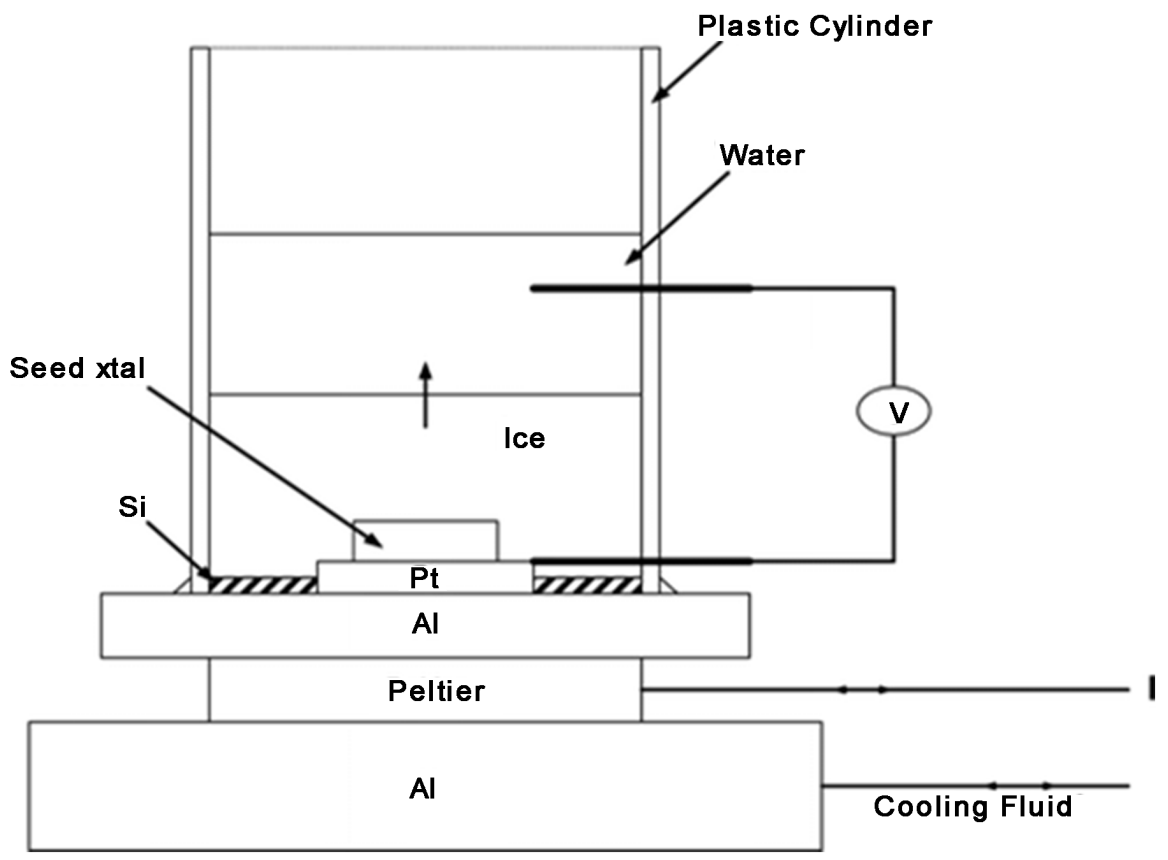

Figure 2. Apparatus used to measure the voltage created between the ice and a dilute salt solution as the ice is grown. The plastic cylinder is $2.5 \mathrm{~cm}$ in diameter and the Peltier module is 65 Watt.

$\mathrm{NaCl}$ at $14 \mathrm{um} / \mathrm{s}$

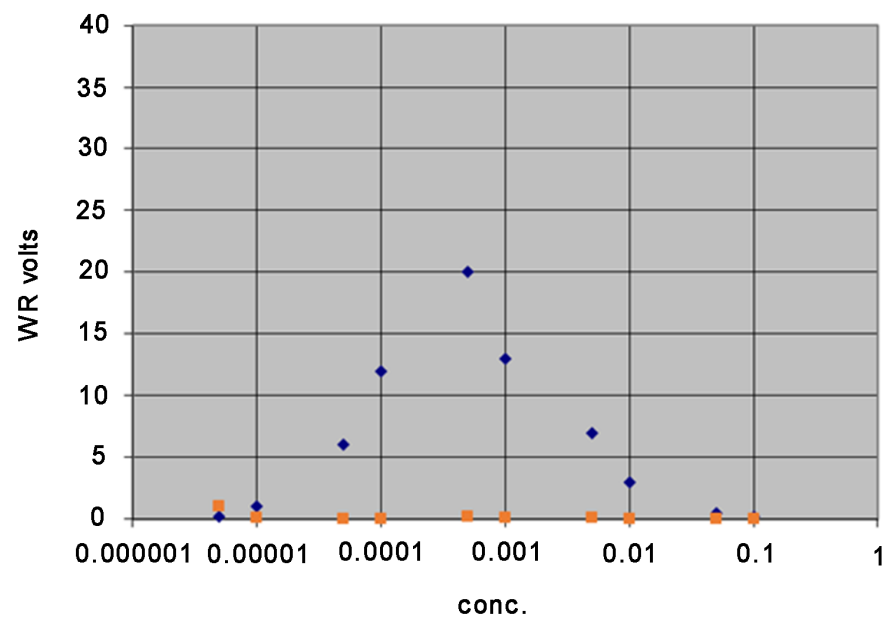

Figure 3. Measured WRFP as a function of concentration for both $\mathrm{NaCl}$ (blue dots 0 and for hydrate formed from tetrahydrofuran (THF) (yellow dots) both types of solid grown as polycrystalline matrices into the dilute solution.

can thus be used as a direct measure of the level of differential ion exclusion, and we see that the hydrate excludes both species equally.

\section{Conclusions}

By measuring the Workman Reynolds Freezing Potential formed by the differential 
ion exclusion occurring as water-ice grows into salt solutions, we have previously calculated that at maximum potential as many as 1 in 3000 ions in the solution are involved [4]. If a chlorine anomaly of as little as 1.5 parts per thousand is thought significant, then reduced $\mathrm{Cl}^{-}$of numbers in the region of 1 in 3000 may well be a factor which needs further consideration. Other considerations involved in this phenomenon will include sea ice growth, high latitude frozen soils, or ice cores, all of which have been studied by experiments using a salt exclusion model [5].

As far as we are aware this is the first report of the comparison of ion exclusion properties using polycrystalline solids of both water ice and THF hydrate and represents a line of investigation in need of further consideration, particularly for those involved in using $\mathrm{Cl}^{-}$anomalies for hydrate exploration in areas where water ice may form, or may have formed either during the hydrate formation or during the test measurements. Our results will be useful for the confirmation of molecular models of the ice/water interface, such as the recent work of Nagata et al. [14]. Next steps might now be to look at other hydrate formers at one atmosphere such as cyclopentane and then to move to high pressure systems such as methane.

\section{References}

[1] Liu, B., Yuan, Q., Su, K.H., Yang, X., Wu, B.C., Sun, C.Y. and Chen, G.J. (2012) Experimental Simulation of the Exploitation of Natural Gas Hydrate. Energies, 5, 466-493. https://doi.org/10.3390/en5020466

[2] Haeckel, M., Suess, E., Wallman, K. and Rickert, D. (2004) Rising Methane Gas Bubbles Form Massive Hydrate Layers at the Seafloor. Geochimica et Cosmochimica Acta, 68, 4335-4345. https://doi.org/10.1016/j.gca.2004.01.018

[3] Heeschen, K. U., Haeckel, M., Klaucke, I., Ivanov, M.K. and Bohrmann, G. (2011) Quantifying in-Situ Gas Hydrates at Active Seep Sites in the Eastern Black Sea Using Pressure Coring Technique. Biogeosciences, 8, 3555-3565.

https://doi.org/10.5194/bg-8-3555-2011

[4] Wilson, P.W. and Haymet, A.D.J. (2008) Workman-Reynolds Freezing Potential Measurements between Ice and Dilute Salt Solutions for Single Ice Crystal Faces. Journal of Physical Chemistry B, 112, 11750-11755. https://doi.org/10.1021/jp804047x

[5] Wilson, P.W. and Haymet, A.D.J. (2008) Comment on "Workman-Reynolds Freezing Potential Measurements between Ice and Dilute Salt Solutions for Single Ice Crystal Faces". Journal of Physical Chemistry B, 112, 15260-15260. https://doi.org/10.1021/jp807642s

[6] Hesse, R. (2003) Pore Water Anomalies of Submarine Gas-Hydrate Zones as Tool to Assess Hydrate Abundance and Distribution in the Subsurface: What Have We Learned in the Past Decade? Earth-Science Reviews, 61, 149-179. https://doi.org/10.1016/S0012-8252(02)00117-4

[7] Ussler, W. and Paull, C.K. (1995) Effects of Ion Exclusion and Isotopic Fractionation on Pore Water Geochemistry during Gas Hydrate Formation and Decomposition. Geo-Marine Letters, 15, 37-44. https://doi.org/10.1007/BF01204496

[8] Yong, R.N., Cheung, C.H. and Sheeran, D.E. (1979) Prediction of Salt Influence on Unfrozen Water Content in Frozen Soils. Engineering Geology, 13, 137-155. 
https://doi.org/10.1016/0013-7952(79)90027-9

[9] Workman, E.J. and Reynolds, S.E. (1950) Electrical Phenomena Occurring during the Freezing of Dilute Aqueous Solutions and Their Possible Relationship to Thunderstorm Electricity. Physical Review, 78, 254-260.

https://doi.org/10.1103/PhysRev.78.254

[10] Caranti, J.M. and Illingworth, A.J. (1980) Surface Potentials of Ice and Thunderstorm Charge Separation. Nature, 284, 44-46. https://doi.org/10.1038/284044a0

[11] Finnegan, W.G. and Pitter, R.L. (1997) Ion-Induced Charge Separations in Growing Single Ice Crystals: Effects on Growth and Interaction Processes. Journal of Colloid and Interface Science, 189, 322-327. https://doi.org/10.1006/jcis.1997.4829

[12] Haymet, A.D.J. and Wilson, P.W. (2017) The Workman-Reynolds "Freezing Potential": A New Look at the Inherent Physical Process. Journal of Molecular Liquids, 228, 243-246. https://doi.org/10.1016/j.molliq.2016.07.081

[13] Wilson, P.W. and Haymet, A.D.J. (2010) Effect of Ice Growth Rate on the Measured Workman-Reynolds Freezing Potential between Ice and Dilute $\mathrm{NaCl}$ Solutions. Journal of Physical Chemistry B, 114, 12585-12588.

https://doi.org/10.1021/jp105001c

[14] Nagata, Y., Ohto, T., Backus, E.H.G. and Bonn, M. (2016) Molecular Modeling of Water Interfaces: From Molecular Spectroscopy to Thermodynamics. Journal of Physical Chemistry B, 120, 3785-3796. https://doi.org/10.1021/acs.jpcb.6b01012 